\title{
Application of Six Sigma to Improve Smartphone Lens Holder Quality - An Empirical Study
}

\author{
Chien-Chih Wang*, Hsin-Tzu Chang, Kai-Yuan Cheng \\ Department of Industrial Engineering and Management Ming Chi University of Technology, New Taipei, Taiwan
}

*Corresponding Author: ieccwang@mail.mcut.edu.tw

\begin{abstract}
In recent years, the market environment and customer ecology were rapid changes. Under the increasingly stringent product specifications, how to efficiently optimize the quality to meet customer demands, has become a crucial issue to maintain the competitiveness of enterprises. In this paper, focused on the quality problem of smartphone lens holder in the development stage based on the design for six sigma approaches to overcome the current quality bottlenecks. The result showed that application of the research results to develop products that can pass the environmental reliability test. The process capability indicator Ppk also increased to 2.22 form 1.41 and to achieve the manufacturer's setting challenge goals.
\end{abstract}

Keywords: QFD, FMEA, DMADV, Design of Experiment, Reliability Test.

\section{Introduction}

Smartphones have continued to develop rapidly in recent years. The rapid expansion is accompanied by manufacturers that are required to be low unit price, rapid production, capacity maximization, product weight is light. As for the main parts of the camera module, since the allplastic lens can satisfy this characteristic, it has become the focus of the manufacturers' active research and development. The Voice Coil Motor (VCM) actuator is a critical component of the camera lens. Its function is the automatic focus of the camera. With smartphones for improving the function of the camera, in order to avoid quality affected by vibration, the handshake-proof function of voice coil motor actuator, has gradually become the standard products. As manufacturers of stepper motors are forced to downsize and reduce manufacturing costs, this will require a breakthrough in the design architecture of the actuator. At present, most phase module manufacturers use piezoelectric actuators for research and development. In this study, the product of the lens holder imported into the camera was developed cooperatively on the smartphone. During the development stage of T6XX, when the manufacturing process encountered customers reported bottlenecks or problems, $\mathrm{U}$ company, which cooperated with industry and universities, applied the DMADV program of six-sigma to solve the bottleneck of extending the product development cycle.

$R \& D$ and design capability is an indispensable decisive key for enterprises in the increasingly fierce international competition in the future, and six-sigma technology are the key. The operation of six-sigma can be divided into two stages, namely, manufacturing DMAIC and design DMADV $[1,2,3]$. In manufacturing, the focus is on making production and business processes more efficient, eliminating errors and defects to save costs. In the use of emphasis on "Extinguishing", that is, to find problems and repair, improve. Although DMAIC has been from the QCC internal brainstorming to solve the problem level, promoted to crossdepartmental problem solving, but it still stays at the level of "firefighting", really want to be able to achieve "prepare for a storm, take precautions", "fire prevention" is the way to solve the root cause $[4,5]$.

The DMADV pointcut starts at the source, either by developing the product or by redesigning the process itself. If the process or product is well designed at the beginning, such defects, complaints, and variations will be greatly reduced due to the careful consideration of Voice of Customer (VOC) in the early stage. The DMADV approach is a fireproof mechanism, usually started by organizing a team of teams, then assessing customer needs, followed by functional analysis, concept development, and then a detailed product or process design and related control plan. In the above steps, all possible problems have been taken into consideration in advance, so that the best protection effect can be obtained, and the chance of "misfire" (referring to defects or defects) will be greatly reduced $[6,7]$.

The literature on the use of design of six sigma in product development and design. Cheng et al., used 
DMADV (Define, Measure, Analyze, Design, Verify) in the development model of advanced smartphones, and the return rate of its benefits decreased significantly from $5.05 \%$ to $1.23 \%$ in the first year [8]. Lin et al., applied DMADV to improve the design quality of ODM electronic products, and its return rate increased from 3.52 standard deviation before improvement to 4.65 standard deviations after improvement in the first year [9].

\section{Methodology}

In this study, we first understand the cooperative manufacturers, the product quality to be improved and the results of the improvement in the past. Then, under the sixsigma framework, integrate appropriate quality tools to develop customized six sigma technology to improve the product design quality to meet customer needs. The proposed analysis program mainly includes five steps, namely definition, measurement, analysis, design and verification.

\subsection{Step 1 : Define Phase}

This stage focus on customer voice collection, collation and analysis. First, discuss with the customer, and get the customer needs and priority order of outstanding quality after preliminary consensus. Then, through Quality function Deployment (QFD), every stage of production is integrated into customer requirements and transformed into product development and design. Is listed first on the MID (Molded Interconnect Device) needs of customers in the process list, and then find out the importance of process and list the MID process operation process, the link between customer demand and process and influence degree of correlation analysis. After transforming the customer's voice into the quality function, SIPOC is used to analyze and evaluate critical production process management. The SIPOC model is an organizational system model, a common technique for process management and improvement, and a preferred method for identifying core processes.

\subsection{Step 2: Measure Phase}

This stage focuses on the evaluation of the performance required by the customer. The primary analysis methods are measurement system analysis (GRR) and process capability analysis. Since measuring instruments will be used to test product characteristics, it is necessary to confirm the accuracy of measuring instruments and the correctness of personnel operation, to ensure the accuracy and reliability of data of instruments. Because once using incorrect data to perform the analysis, it will lead to wrong judgment, and cannot find a suitable solution. The measuring instrument used in this study is a microdensitometer, which is used for the inspection of measuring impedance values. Then, understand the part of the current status of the product process, analyze the processability index of the product proofing stage. Due to the lack of previous experience for reference and improvement in the early stage of product or process development, this study evaluated the process capability analysis after sampling 30 samples from the first proofing products and used Ppk to calculate the process capability index.

\subsection{Step 3 : Analyze Phase}

In this stage, the failure mode and effect analysis (FMEA) in the risk assessment tool is used to analyze the production process and process. FMEA is a preventive reliability technique designed to identify and evaluate potential failures and impacts in a product/process and to develop specific measures to prevent/reduce these potential failures. To be specific, the use of FMEA management mode can identify risks in the project in the early stage, which can help manufacturers improve production efficiency and shorten the time to market of products.

\subsection{Step 4 : Design Phase}

The stage focuses on the analysis and optimization of critical factors. In the six-sigma process, the optimization stage is usually the most time-consuming and laborious, which requires not only the cost and time to collect relevant experimental data, but also the assistance of professionals familiar with statistics and quality control tools. However, the results of this phase analysis will bring significant benefits to the improvement project. In this stage, controllable factors and uncontrollable factors will be identified, and significant factors that have a high impact on the process will be listed as critical parameters. In this study, considering the customer's product development time requirements, after discussion with the process department, we decided to conduct the laser parameter levelling interval experiment with LCP bare plate. In order to reduce the variability of the experiment and improve the accuracy of the experiment, factors (controllable factors) that may affect impedance were selected before the experiment. Then independent $t$-test was used to confirm whether the factors were significant to the response value through the results of two-sample $t$. Finally, the design of the experiment is designed to optimize the critical quality of the lens holder. The objective is to estimate the parameters of the small impedance of the lens holder of the mobile phone camera. To establish the relationship between the mean value and the variance, to optimize the parameters. During the experiment, we will synchronously confirm whether the parameter changes will have side effects on the product quality. 


\subsection{Step 5 : Verification Phase}

This stage focuses on verifying whether the design performance and capability can meet customer needs. Peeling test and High-Temperature High Humidity story-test (HHT) and Temperature Cycling test (TC) used in environmental reliability test will be used in this study to ensure that the product design can meet customer specifications and reduce the probability of customer complaints and returns. High temperature and high humidity test is a significant part of the reliability test. Cold and heat shock is a useful technology, which can expose the problems of products in advance, make right quality products can be used generally through screening, and leave the potential problems for maintenance or elimination, so that the quality of ex-factory products can remain stable, reduce the maintenance cost, and benefit both manufacturers and users.

\section{Analysis and Discussion}

The case study of the company belongs to the electronics manufacturing industry. In the production process of mobile phone communication antenna, when quality abnormalities occur or customers respond to quality problems, PDCA and 8D report are currently used to deal with quality problems. However, it was found in new product development that the improvement process using PDCA alone could not meet the expectations of customers. This study takes autofocus VCM as the research object. The product structure is composed of the magnet, coil, upper and lower reed, upper and lower gasket, shell, carrier and base. The product LH is one of the main parts of VCM and belongs to the production stage of the front end in the whole component supply chain. The final shipment quality of LH is one of the important factors that determine whether the VCM can operate normally. At present, LH has been tested by the manufacturer for the first time and found the problem of high-power consumption.

\subsection{Execution definition phase}

The Industry-university cooperation company is the first to import the phone lens holder components into the 3D-MID process. In the first sample development test, it was found that the product consumes high power, which may be caused by high impedance value after customer analysis. After a meeting between the case company and the product developer, the supplier was defined as plastic injection moulding manufacturer, the input was raw material inspection, the process was laser processing, the output was roller plating processing, and the customer was the final inspection station. The process of drawing SIPOC was defined. After QFD, it is found that the first three essential qualities are laser circuit design, laser circuit production and product cleaning. Therefore, the laser processing process is the main stage of the quality key, and the following will confirm the laser processing process and analyze the critical quality items.

\subsection{Execution measurement phase}

In the customer inspection specification, the impedance of the phone lens holder is measured using a micro resistor meter. Gage R\&R was used in this study to verify whether the micro resistor meter is reliable. A random collection of 90 data, calculated by Minitab $18 \AA$, found that GR\&R was $24.72<30 \%$ and $\mathrm{NDC}=5$, indicating that the measured data of the measurement system is reliable, and Figure 1 shows the results of GR\&R analysis.

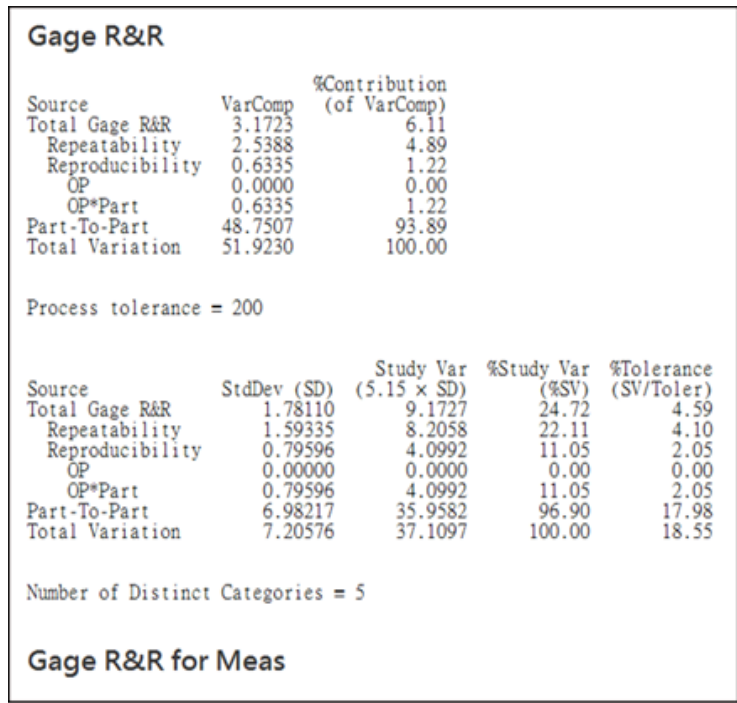

Fig.1. The analysis result of MSA for the micro resistor meter

Next, understand current process capabilities and identify targets for improvement, and list the ownership process parameters that affect the response value. This product did not have any relevant process capability data for reference in the past, so we collected the samples of customers' first proofing for process capability analysis. Figure 2 shows the calculation result of Minitab $18 \AA$, showing that the Ppk value is 1.09 , which is still some distance away from the target of the case manufacturer, indicating that have room for improvement in the MID process for mobile phone lens holder products.

\subsection{Execution analysis phase}

This phase used FMEA to analyze the product development process and identify the risks in the process. Evaluate the severity (S), occurrence (O) and detection (D) of each process and provide improvement measures for the process with high $\mathrm{RPN}=\mathrm{S} \times \mathrm{O} \times \mathrm{D}$ risk index. The summarized the FMEA analysis and improved results in Table 1. From Table 1 that the improvement rate can reach 
up to $20 \%$, indicating a good improvement result.

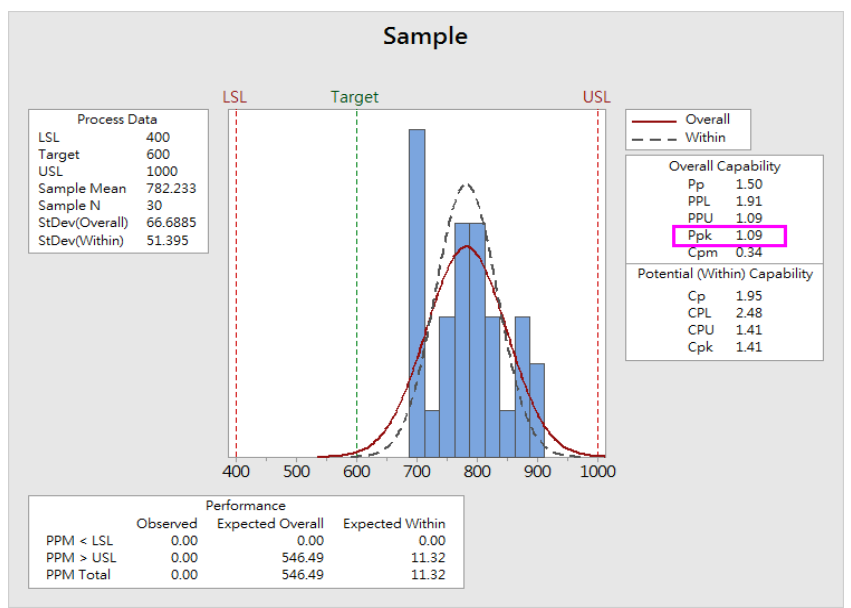

Fig.2. Results of the lens holder process capability analysis

Table 1. The FMEA analysis results

\begin{tabular}{|c|c|c|c|c|}
\hline $\begin{array}{c}\text { Design } \\
\text { requirements }\end{array}$ & $\begin{array}{c}\text { Improved } \\
\text { RPN before }\end{array}$ & Improve strategy & $\begin{array}{c}\text { Improved } \\
\text { RPN }\end{array}$ & $\begin{array}{l}\text { Improve } \\
\text { ment rate }\end{array}$ \\
\hline $\begin{array}{l}\text { Line wiring is } \\
\text { complete } \\
\text { without offset } \\
\text { or gap }\end{array}$ & 224 & 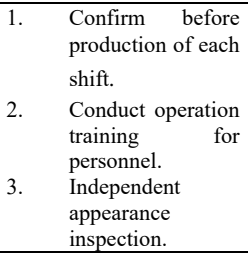 & 192 & $14.29 \%$ \\
\hline Complete line & 280 & $\begin{array}{l}\text { 1. } \begin{array}{l}\text { Independent } \\
\text { appearance } \\
\text { inspection. } \\
\text { Confirm the laser } \\
\text { program (4hr/1 } \\
\text { time) }\end{array}\end{array}$ & 240 & $14.29 \%$ \\
\hline $\begin{array}{l}\text { The ray path is } \\
\text { not burnt or } \\
\text { pale }\end{array}$ & 210 & $\begin{array}{ll}1 . & \begin{array}{l}\text { Independent } \\
\text { appearance } \\
\text { inspection }\end{array} \\
\text { 2. } & \begin{array}{l}\text { Confirm the laser } \\
\text { program (4hr/1 } \\
\text { time) }\end{array}\end{array}$ & 175 & $16.67 \%$ \\
\hline $\begin{array}{l}\text { Strike copper } \\
\text { plating }\end{array}$ & 210 & 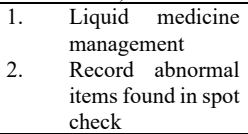 & 168 & $20.00 \%$ \\
\hline
\end{tabular}

3.4 Execution design phase

After QFD and FMEA analysis, the laser process was selected for DOE impedance optimization. After brainstorm by the company personnel, after removing uncontrollable factors and patent factors of equipment and raw material suppliers, only laser energy (factor A), laser frequency (factor B) and film thickness (factor C) were considered. The levelling setting refers to the definition of LPKF, the original equipment supplier of the laser, and the laser energy levelling range is $1.5,2.0$ and $2.5 \mathrm{w}$. Laser frequency levelling range 60,80 and 100KHz; Film thickness levelling range 8, 11 and $14 \mathrm{um}$. Consider the process interval of process capability and resource and plan the execution of $2^{\mathrm{k}}$ plus the centre point to repeat the experimental design. In this study, the experimental impedance of the product was measured under each experimental combination.
The figure 3 shows the ANOVA analysis results, and found that the $\mathrm{p}$-values of $\mathrm{A}, \mathrm{B}$, and $\mathrm{C}$ are all $<0.05$, which indicates that these three factors are all significant, and the p-values of interaction terms $\mathrm{AB}, \mathrm{AC}, \mathrm{BC}$, and $\mathrm{ABC}$ are all $<0.05$, indicating that the second-order and third-order interactions are all significant factors. Then, the regression model established by the significant factor is used to estimate the parameters corresponding to the optimal reaction value. Figure 4 can find, will be process parameters (A, B, C), respectively, set in $(2.5,60,14)$ can get the best predict response value of $428.3123 \mathrm{~m} \Omega$ impedance values.

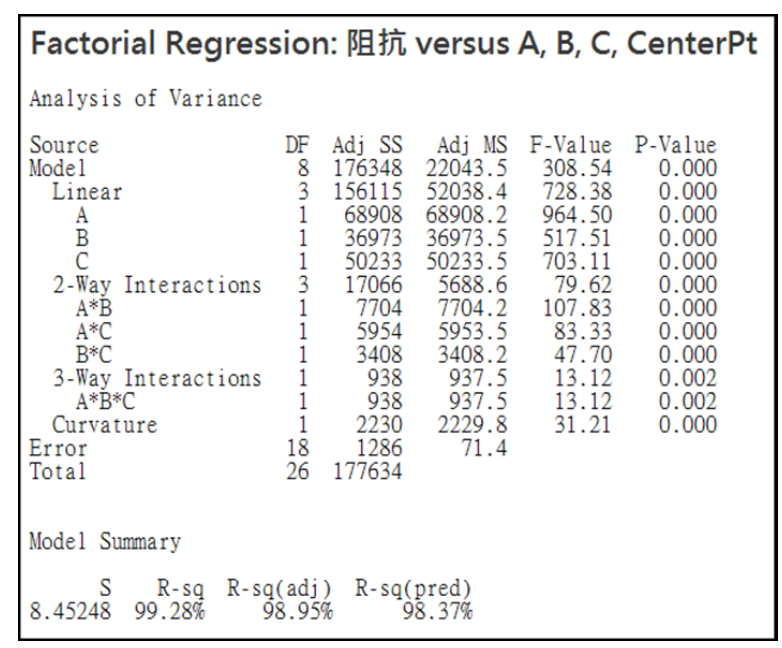

Fig 3. The analysis result of ANOVA

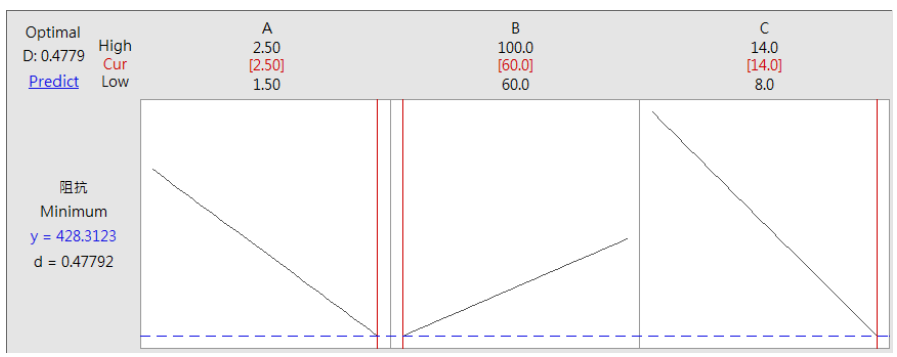

Fig.4. Results of optimizing process parameter combinations

\subsection{Execution verification phase}

The verification experiment was conducted by combining the obtained optimal parameters into ten groups. According to the measured data and statistical analysis, the results showed that the maximum and minimum values of the response variable impedance (y) both fell within the predicted range $(423.28,455.38)$. Then, confirm the feasibility of the optimum yield and analyze the improved process capability. According to the analysis results, Ppk increased from 1.09 to 2.12 after improvement. The product is sent to the customer for verification, and the customer feedback results are consistent with the results of this study, and the impedance value is improved by $28.57 \%$.

Finally, perform the verification operation after the 
critical quality improvement. Perform environmental reliability testing, impedance testing after high temperature, high humidity and cold and heat shock testing. In the way of Before \& After comparison of experimental data, the stable range of quality was observed (determined by the product developer, and the average variable rate was $\leqq 10 \%$ ). The test results showed that there were three sets of data close to $10 \%$. After observing the appearance of the product without abnormal quality, the reliability test results were determined to be passed.

\section{Conclusion}

The application of 3D metal wire manufacturing technology (3d-mid) has expanded from the early antenna products of mobile phones, such as GPS antenna, main antenna, wi-fi antenna, etc., to the application scope of the smartphone camera module in recent years. With the trend of intelligence and miniaturization, the development of $3 \mathrm{~d}-\mathrm{mid}$ technology will have infinite imagination space. This study takes the case of the improvement project promoted by the case company in 3d-mid optimization of mobile phone lens holder as an example to discuss how to effectively promote six-sigma DMADV in practice and achieve the set quality improvement target. According to the analysis and empirical results, the proposed method is feasible and consistent with the improvement of new product development.

\section{References}

(1) Mouaky, M., Benabbou, L., \& Berrado, A. "DMADV approach to evaluate the Adaptive Kanban performance for inventory management process: the case of Moroccan public pharmaceutical supply chain ", In Supply Chain Forum: An International Journal, Vol. 19, No. 3, pp. 178-190, 2018.

(2) Smętkowska, Monika, \& Beata Mrugalska. "Using Six Sigma DMAIC to improve the quality of the production process: a case study ", Procedia-Social and Behavioral Sciences, Vol. 238, pp.590-596, 2018.

(3) Sharma, G. V. S. S., Rao, P. S., \& Babu, B. S. "Process capability improvement through DMAIC for aluminum alloy wheel machining ", Journal of Industrial Engineering International, Vol.14, N0.2, pp.213-226, 2018.

(4) De Mast, Jeroen, \& Joran Lokkerbol. "An analysis of the Six Sigma DMAIC method from the perspective of problem solving", International Journal of Production Economics, Vol.139, No.2, pp.604-614, 2012.

(5) Yousef, Nadin, \& Farah Yousef. "Using total quality management approach to improve patient safety by preventing medication error incidences", BMC health services research, Vol.17, No.1, p.621, 2017.

(6) Jiang, Jui-Chin, Cheng-Hsing Hsu, \& Hung-Son Dang. "Investigating the Designed Parameters of Dual-Layer Micro-Channel Heat Sink by Design for Six Sigma (DFSS)", International Conference on Applied System Innovation (ICASI), 2017.

(7) Chan, Ku-Chi, Ying Ho, \& Chuen-Sheng Cheng. "Using six sigma methodology to improve the copper plating uniformity in flip chip ball grid array", Journal of quality, Vol.26, No.2, pp.114-125, 2019.

(8) Cheng, Chuen-Sheng, Shih-Chieh Lee, Pei-Wen Chen, $\&$ Kuo-Ko Huang. "The application of design for Six Sigma on high level smart phone development", Journal of quality, Vol.19, No.2, pp.117-136, 2012.

(9) Lin, C. S., Chen, L. F., \& Yu, H. C. "Application of DFSS for ODM electronic product development-an empirical study of a wireless communication company". Journal of quality, V0.17, N0.6, pp.501-526, 2010. 